\title{
Nicotine and the dopaminergic output of the ventral tegmental
}

\section{area}

\author{
Michael Graupner*1,2 and Boris Gutkin ${ }^{1}$
}

\author{
Address: ${ }^{1}$ Group for Neural Theory, École Normale Supérieure, Collège de France, France and ${ }^{2}$ Laboratoire de Neurophysique et Physiologie, CNRS \\ UMR 8119, Université Paris Descartes, France \\ Email: Michael Graupner* - michael.graupner@ens.fr \\ * Corresponding author
}

from Seventeenth Annual Computational Neuroscience Meeting: CNS*2008

Portland, OR, USA. 19-24 July 2008

Published: II July 2008

BMC Neuroscience 2008, 9(Suppl I):P46 doi:10.1 I86/I47|-2202-9-SI-P46

This abstract is available from: http://www.biomedcentral.com/I47I-2202/9/SI/P46

(C) 2008 Graupner and Gutkin; licensee BioMed Central Ltd.

Midbrain dopaminergic neurons (DA) are thought to convey information about the rewarding or motivationally relevant properties of external stimuli. Furthermore, evidence has accumulated that dopamine signaling is involved in the rewarding and aversive motivational properties of drugs of abuse, including nicotine. DA neurons project from the ventral tegmental area (VTA) to various structures including the nucleus accumbens (NAcc) and the prefrontal cortex. Like other drugs of abuse, nicotine increases dopamine levels in the NAcc. While nicotinic acetylcholine receptors (nAChRs) are expressed throughout the central nervous system, this increase has been demonstrated to result from a direct stimulation of nAChRs in the VTA [1]. Nicotine concentrations reached during smoking activate and subsequently desensitize nAChRs. However, the mechanism of how the dopaminergic signal in response to nicotine exposure is constructed in the VTA remains elusive. Especially, in vitro and in vivo recordings from the VTA during nicotine exposure reach different conclusions about the underlying VTA circuitry and localizations of nAChRs in the VTA $[2,3]$.

The VTA contains dopaminergic and GABAergic cells which receive cholinergic input from the laterodorsal and the pedunculopontine tegmental nuclei and glutamatergic input originating in part from the prefrontal cortex. The response of DA neurons to endogenous acetylcholine and exogenous nicotine is mediated by nAChRs expressed on three different cell types: (i) on the DA neurons themselves, (ii) on the VTA GABAergic neurons, and (iii) on glutamatergic inputs from various brain structures. VTA
DA neurons exhibit firing activities ranging from a slow regular single-spike firing to a bursting mode. Interestingly, the burst-firing mode generates a substantially larger increase of DA release than regular spiking. We describe the VTA by a neural network model which accounts for the two main neuron populations in the VTA - dopaminergic and GABAergic neurons, the local connectivity between both, and the presence of specific nAChR subtypes. We constructed both: (i) a population activity model and (ii) a spiking neuron model of the VTA.

Based on known activation and desensitization properties of nAChRs, we investigate the DA neuron activity in the VTA in response to nicotine exposures. We show that the in vitro and in vivo data can be reconciled by changing the afferent input strength but keeping the VTA circuitry unchanged. These investigations allow us to make qualitative statements about the distribution and localization of nAChRs. Beyond the reproduction of experimental data on nicotine exposures, we use the model to make predictions about how glutamatergic and cholinergic input to the VTA is translated into changes of DA neuron activity and how such processing is altered in the presence of nicotine. Moreover, we utilize the spiking neuron model to disentangle the specific contributions of input pathways to changes in regular spiking and bursting activity of DA neurons. These investigations can help to understand how the VTA contributes to the rewarding properties of nicotine. 


\section{References}

I. Di Chiara G: Role of dopamine in the behavioural actions of nicotine related to addiction. Eur J Pharamacol 2000, 393:295-314.

2. Mansvelder HD, Keath JR, McGehee DS: Synaptic mechanisms underlie nicotine-induced excitability of brain reward areas. Neuron 2002, 33:905-919.

3. Mameli-Engvall M, Evrard A, Pons S, Maskos U, Svensson TH, Changeux JP, Faure P: Hierarchical control of dopamine neuron-firing patterns by nicotinic receptors. Neuron 2006, 50:9||-92|.

Publish with Bio Med Central and every scientist can read your work free of charge

"BioMed Central will be the most significant development for disseminating the results of biomedical research in our lifetime. " Sir Paul Nurse, Cancer Research UK

Your research papers will be:

- available free of charge to the entire biomedical community

- peer reviewed and published immediately upon acceptance

- cited in PubMed and archived on PubMed Central

- yours - you keep the copyright

Submit your manuscript here:

http://www.biomedcentral.com/info/publishing_adv.asp 